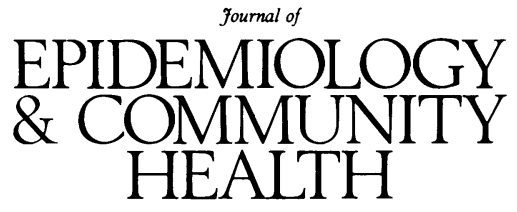

\title{
Editorial \\ Causes and control of chronic respiratory disease: looking beyond the smokescreen
}

Cigarette smoking is as strongly related to death from chronic bronchitis and emphysema as it is to mortality from lung cancer. $^{1}$ Symptoms of cough, phlegm, wheeze, and breathlessness are also much more common among individuals and populations who smoke, and are reduced when they quit the habit. ${ }^{2}$ A randomised controlled trial reported in this issue ${ }^{3}$ reinforces the simple public health message: when it comes to cigarettes, a change is not as good as a rest.

Cigarette smoking in many developed countries is on the decline (though regrettably increasing in popularity elsewhere). In Britain, current smokers have been in the minority among adults of both sexes since the late 1970 s and, if current trends continue, less than one quarter of the population will be active smokers by the year 2000 . How will the problem of chronic respiratory disease change as smoking declines and other causes which have for so long been obscured by the effects of smoking increasingly require investigation and control?

It is likely that, even if smoking were entirely eliminated, a substantial burden of chronic respiratory morbidity would remain. Respiratory symptoms and illnesses are not uncommon in lifelong non-smokers, as illustrated by data from the British 1946 cohort reported in this issue. ${ }^{4}$ Reduced levels of ventilatory function would also remain of concern as a risk factor for (even if not a cause of) all mortality. ${ }^{5}$

The decline in smoking among British men in recent decades has been accompanied by a fall in the prevalence of phlegm and breathlessness, but not of wheeze, despite the fact that wheeze is more commonly reported by cigarette smokers. ${ }^{2}$ This suggests that morbidity related to asthma may become of relatively greater importance as smoking declines. The relationships of allergy and asthma to mucus hypersecretion (causing cough and phlegm) and to irreversible airflow obstruction (the main cause of disabling breathlessness and premature death from respiratory disease) are complex. A large volume of related clinical and epidemiological research has not so far identified the direction of cause and effect. ${ }^{6}$ Although these syndromes often coexist, particularly in persons who smoke, it is likely that each has distinct causes and mechanisms, which may be clarified by aetiological research among non-smokers.

The review of findings from the 1946 cohort $^{4}$ is a timely reminder that factors other than smoking play a role in the causation of chronic respiratory disease in adults, and that these influences may operate from an early age. Such factors may acquire increasing prominence in aetiological research and preventive programmes as the prevalence of smoking declines.

\section{Childhood chest illness}

The association between chest illnesses in childhood and later respiratory morbidity is now well documented. ${ }^{4-9}$ It appears to be largely independent of socioeconomic confounding, but the underlying mechanism remains unclear. Do chest illnesses damage the lung, or are some individuals susceptible to chest illnesses of all types from an early age through to adult life?

The intriguing observation from the 1946 cohort of familial aggregation of respiratory morbidity spanning three generations ${ }^{4}$ suggests a degree of constitutional susceptibility to all forms of respiratory illness, but this does not fully account for the association between illness and later chest problems in this cohort. Asthma has been suggested as a possible link between chest problems in childhood and in later life. ${ }^{8}$ Unfortunately, rather limited information is available about wheezing illness in childhood for the 1946 cohort, but more extensive data are available in the later national cohorts born in 1958 and 1970. Prospective studies of these groups may help to clarify the natural history of chest illness from childhood to early adult life.

A potential problem with such studies is that the nature and severity of chest illnesses in early childhood have probably changed considerably over the past century. Thus findings from prospective studies of postwar cohorts do not necessarily explain the distribution of disease in the generations currently demanding clinical care for chronic obstructive airways disease. The recent report of a historical cohort study of Hertfordshire men in their $60 \mathrm{~s}$ is therefore of particular interest. Whooping cough, bronchitis, and pneumonia were each associated with a significant deficit in ventilatory function, but only if acquired during the first year of life. ${ }^{9}$ This contrasts with reports from the 1946 cohort, ${ }^{410}$ where neither childhood whooping cough nor early bronchitis or pneumonia independently affected peak expiratory flow rate at age 36 years. If these inconsistencies are not due to chance or to unrecognised confounding, are they attributable to the age at which lung function was measured, or had the clinical severity of early chest illnesses already declined by the middle of the century, before antibiotics and pertussis immunisation were introduced?

\section{Socioeconomic status}

One of the most puzzling yet consistent features of chronic respiratory disease, at least in Britain, has been its marked social class gradient, with a predilection for the least privileged groups. Smoking and occupational exposures are probably only part of the explanation. An important and topical issue is the extent to which such socioeconomic gradients reflect upbringing and living conditions in childhood, or lifestyle and environment in adult life.

Ventilatory function in late middle age is a function of the functional capacity achieved during lung growth, and the rate of subsequent irreversible airflow obstruction which varies greatly between individuals. Upon this may be superimposed a reversible obstructive component, typically related to asthma. 
Thus it is plausible to suggest that symptomatic chronic respiratory disease might be influenced by exposures during lung growth (before or after birth), or during the phase of lung function decline (in adult life), or both.

Studies of geographically mobile groups give conflicting results. Historically, emigrants from Britain appear to retain a high risk of chronic bronchitis when they settle in other countries. ${ }^{11}$ On the other hand, among internal migrants within England and Wales, the risk of fatal chronic bronchitis or emphysema (at least as defined by proportional mortality) is more closely related to place of death than to place of birth. ${ }^{12}$

Strong associations are shown in the analysis of the 1946 cohort between socioeconomic circumstances in childhood (particularly domestic crowding), adult asthma/wheeze, and impaired ventilatory function. ${ }^{4}$ Although these are adjusted for smoking, no mention is made of adult social status. More specific studies of socially mobile individuals would be useful to distinguish the separate influences of childhood and adult experience.

A number of recent observations may be relevant to the explanation of social class trends in chronic respiratory disease, and each, in its own right, opens an exciting new research agenda.

In the aforementioned survey of Hertfordshire men, ${ }^{9}$ reduced levels of ventilatory function and increased mortality from chronic respiratory disease were observed among men of low birthweight. Intrauterine growth retardation could plausibly result in submaximal lung capacity in early adult life, but a normal rate of functional decline might be expected thereafter. With obstetric records and peak expiratory flow measurements at ages 36 and 43 years (the latter unpublished), the 1946 cohort should be well placed to clarify the relationships between birthweight, maximal ventilatory capacity, and rate of functional decline.

Other studies have suggested a link between diet and respiratory disease. At first sight this seems improbable, but closer consideration of pathogenesis and the few epidemiological observations that are available suggest that it may deserve greater attention.

The marked increase in risk of emphysema among individuals with a genetically determined deficiency of $\alpha-1$ antitrypsin suggests that the balance in lung tissue between destructive proteases and protective antiproteases (including $\alpha-1$-antitrypsin) may be of importance in determining the rate of loss of ventilatory function during adult life. Tissue levels of antioxidants, such as the vitamins $\mathrm{A}, \mathrm{C}$ or $\mathrm{E}$, may be important in maintaining this balance in favour of repair rather than destruction of alveolar tissue.

Cross sectional studies have been reported showing a correlation of frequent fresh fruit consumption with better levels of ventilatory function, ${ }^{13}$ and association of low plasma vitamin $C$ levels with increased risk of doctor diagnosed bronchitis. ${ }^{14}$ Although residual confounding effects are of considerable concern in these studies, further observational and experimental studies can be expected which may clarify the role of antioxidants in both structural and functional lung disease.

It has been suggested that a high sodium intake may increase airway reactivity and thereby symptoms of asthma, at least among men. Although the pathophysiological basis of such a link is less clear than for antioxidant deficiency and emphysema, there is supporting evidence both from observational and experimental epidemiology, at least among men. ${ }^{15} 16$ The inconsistency between men and women is puzzling but may be due to the relatively small numbers hitherto studied. A large international study has been mounted to clarify the contribution of dietary sodium to respiratory morbidity in adults.

\section{Air pollution}

After an interval of two or three decades, air pollution is back on the political and research agenda. Few students of epidemiology are unaware of the acute effects of smoke and sulphur dioxide air pollution in the London smog episode of December 1952. Less well known is the observation that a temporal relationship between daily smoke and daily deaths in Greater London persisted, at least into the mid-1970s, at all levels of particulate pollution; indeed the dose-response relationship was steeper at low levels of pollution. ${ }^{17}$

On the other hand, time trends in mortality from chronic respiratory disease offer no clear evidence of a reduction attributable to the control of smoke and (to a lesser extent) sulphur dioxide air pollution in urban Britain. ${ }^{18}$ This could be because exposure in early life is of particular importance. The 1946 cohort has offered inconsistent evidence on this point, perhaps because the measures of air pollution available at the time were rather crude. Research on later cohorts, for which more widespread pollution measurements are available, may offer further insight. However, they will be limited to assessment of the effects of a limited period of high pollution exposure in childhood, as urban smoke and sulphur dioxide declined substantially from the early 1960 s in Britain. We may need to turn to eastern Europe to rediscover levels of particulate and sulphurous air pollution current at the time the 1946 cohort were born.

Public attention is now focused on the "new" pollutants associated with vehicle emissions and photochemical smog, long thought to be a scourge only of affluent Californians. In December 1991, almost 40 years after the infamous smog, London experienced the highest levels of airborne nitrogen oxides ever recorded in Britain. There have been clearly defined episodes of ozone pollution recorded regularly over the past 15 years. Are such episodes also associated with increased mortality or morbidity, and is this confined to those with pre-existing respiratory conditions? Canadian studies suggest that hospital admissions for asthma were associated with episodes of photochemical air pollution, but the pollution "cocktail" in other countries is probably different. We know too little of the short or long term consequences of recent British episodes to quantify their effect on the health of the population. ${ }^{19}$

\section{Implications for public health}

For the foreseeable future, these developments in aetiological research are unlikely to result in radical changes to current public health strategies. Control of smoking remains the mainstay for prevention of chronic respiratory disease. Air quality guidelines are already published in Europe and America but may be revised in the light of emerging epidemiological evidence. If diet is important for development of asthma or emphysema (and the evidence is sparse at present), then the changes that are likely to be advocated match closely those already recommended for prevention of cardiovascular disease. Additional prospects for prevention of asthma await further aetiological discoveries, including elucidation of the causes of atopic disease in general.

The childhood infections against which vaccination is currently offered (measles and pertussis) do not appear to influence mucus secretion and ventilatory function in adult life in postwar cohorts. Hitherto, vaccines which have been developed against respiratory syncytial virus, arguably the most likely cause of long term lung damage in infancy, have been ineffective or even hazardous. ${ }^{20}$ The most remediable cause of chest illness in the first year of life currently is parental (particularly maternal) smoking. The latter is also the most powerful environmental determinant of low birthweight. It is therefore appropriate that suggested national targets for 
smoking reduction address specifically the problem of smoking among pregnant women and their partners. Unless action in this area is intensified, then it is possible that the smokescreen around respiratory disease will linger for a generation longer than might otherwise be anticipated.

\section{P STRACHAN}

1 Doll R, Peto R. Mortality in relation to smoking: 20 years' observation on male British doctors. BMF 1976; ii: 1525-36.

2 Cook DG, Kussick SJ, Shaper AG. The respiratory benefits of stopping smoking. F Smoking Related Disord 1990; 1: 45-58.

3 Withey CH, Papacosta AO, Swan AV, et al. Respiratory effects of lowering tar and nicotine levels of cigarettes smoked by young male middle tar tar and nicotine levels of cigarettes smoked by young male middle tar
smokers. II. Results of a randomised controlled trial. 7 Epidemiol smokers. II. Results of a randor

4 Mann SL, Wadsworth MEJ, Colley JRT. Accumulation of factors influencing respiratory illness in members of a national birth cohort and their offspring. F Epidemiol Community Health 1992; 46: 286-92.

5 Strachan DP. Ventilatory function, height and mortality among lifelong non-smokers. f Epidemiol Community Health 1992; 46: 66-70.

O'Connor GT, Sparrow D, Weiss ST. The role of allergy and nonspecific airways responsiveness in the pathogenesis of chronic obstructive airways disease. Am Rev Respir Dis 1989; 140: 225-52.

7 Samet JM, Tager IB, Speizer FE. The relationship between respiratory illness in childhood and chronic air-flow obstruction in adulthood. Am Rev Respir Dis 1983; 127: 508-23.
8 Strachan DP, Anderson HR, Bland JM, Peckham C. Asthma as a link between childhood chest illness and chronic cough and phlegm in young adults. BMF 1988; 296: 890-3

9 Barker DJP, Godfrey KM, Fall C, Osmond C, Winter PD, Shaheen SO. Relation of birth weight and childhood respiratory infection to adult lung function and death from chronic obstructive lung disease. BMF 1991; 303: 671-5.

10 Britten $\mathrm{N}$, Wadsworth J. Long term respiratory sequelae of whooping cough in a nationally representative sample. $B M \mathcal{F} 1986 ; 292$ : $441-4$.

1 Reid DD, Fletcher CM. International studies in chronic respiratory disease. Br Med Bull 1971; 27: 59-64.

12 Osmond C, Slattery JM, Barker DJP. Mortality by place of birth. In: Britton M, ed. Mortality and geography. A review in the mid-1980s. (Series DS no. 9.) London: HMSO, 1990: 96-100.

13 Strachan DP, Cox BD, Erzinclioglu SW, Walters DE, Whichelow MJ. Ventilatory function and winter fresh fruit consumption in a random sample of British adults. Thorax 1991; 46: 624-9.

14 Schwartz J, Weiss ST. Dietary factors and their relation to respiratory symptoms. Am $¥$ Epidemiol 1990; 132: 67-76.

15 Burney PG, Britton JR, Chinn S, et al. Response to inhaled histamine and 24 Burney PG, Britton JR, Chinn S, et al. Response to

16 Burney PG, Neild JE, Twort CH, et al. Effect of changing dietary sodium on the airway response to histamine. Thorax $1989 ; 44: 36-41$.

17 Schwartz J, Marcus A. Mortality and air pollution in London: a time series analysis. Am $\mathcal{F}$ Epidemiol 1990; 131: 185-94.

8 Barker DJP, Osmond C. Childhood respiratory infection and adult chronic bronchitis in England and Wales. $B M F$ 1986; 293; 1271-5.

19 Lippmann M. Health effects of ozone. $\mathcal{F}$ Air Pollution Control Assoc 1989; 39: $672-95$.

20 Milner AD, Murray M. Acute bronchiolitis in infancy: treatment and prognosis. Thorax 1989; 44: 1-5. 